\title{
Evaluation of the Electro-Fenton efficiency in removal of antibiotic Metronidazole from aqueous solutions
}

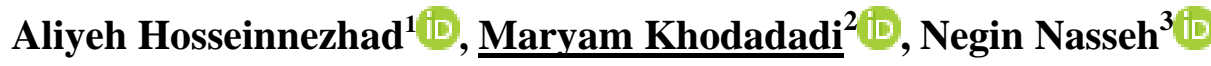 \\ ${ }^{1}$ Student Research Committee,Birjand University of Medical Sciences, Birjand,Iran \\ ${ }^{2}$ Corresponding author; Medical Toxicology and Drug abuse Research Center, Department of Environmental Health Engineering, \\ Birjand University of Medical Sciences, Birjand, Iran. \\ Tel: +985632381661 Fax: +985631631651_ Email: maryam Khodadadi@gmail.com \\ ${ }^{3}$ Social Determinants of Health Research Center, Department of Environmental Health Engineering, Faculty of Health, Birjand \\ University of Medical Sciences, Birjand, Iran.
}

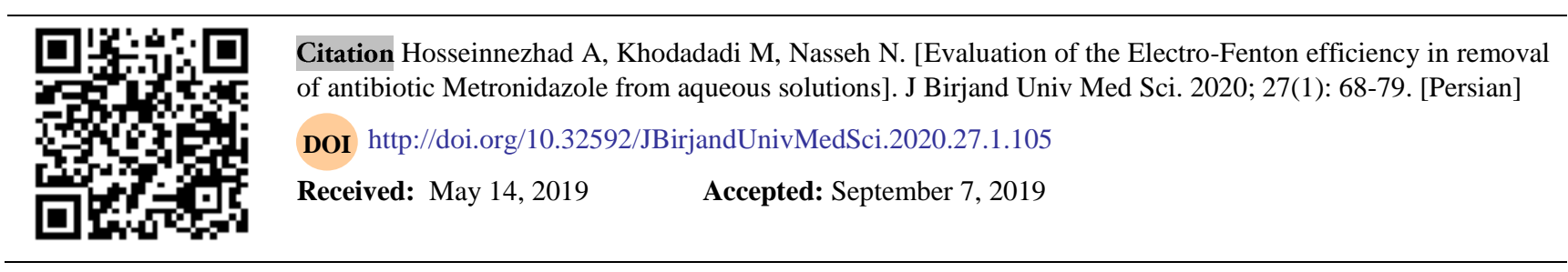

\begin{abstract}
Background and Aim: Metronidazole is one of the antibiotics that are widely used and resistant to biodegradation, it is one of the most important pollutants in the environment. The purpose of the study was to examine the efficacy of the Electro-Fenton process for removing metronidazole from synthetic wastewater using iron electrode under operating different conditions.

Materials and Methods: The present study was an experimental, laboratory-scale study that was done discontinuously. The effect of soluble $\mathrm{pH}$ variables $(11,9,7,5,3)$, initial concentration of metronidazole $(10,15,20,25$ and $30 \mathrm{mg} / \mathrm{L})$, electrode spacing $(0.5,1$, 2 and $3 \mathrm{~cm}$ ), hydrogen peroxide concentration $(50,100,150$ and $200 \mathrm{mg} / \mathrm{L})$ and current intensity $(1,0.5,0.3,0.2$ and $0.05 \mathrm{~A})$ with the mixing rate of 100 RPM at ambient temperature was investigated. The reaction kinetics was also studied. The antibiotic concentration was read by UV / Vis T80 + spectrophotometer at $320 \mathrm{~nm}$ wavelength.
\end{abstract}

Results: The results showed that at optimum conditions ( $\mathrm{pH} \mathrm{7,120} \mathrm{minutes,} \mathrm{antibiotic} \mathrm{concentration} 20 \mathrm{mg} / \mathrm{L}$, the hydrogen peroxide concentration $150 \mathrm{mg} / \mathrm{L}$, inlet current intensity of $0.05 \mathrm{~A}$ and electrode spacing of $1 \mathrm{~cm}$ ), The removal efficiency of metronidazole by Electro-Fenton process was $96.37 \%$.

Conclusion: According to the results, it was found that Electro-Fenton with iron electrodes can be used as an effective method in the removal of metronidazole from aqueous solutions.

Key Words: Antibiotic; Aqueous Solutions; Electro-Fenton; Iron Electrode; Metronidazole 


\title{
بررسى كار آيى فر آيند الكتروفنتون در حذف آنتىبيوتيك مترونيدازول از محلولهاى آبى
}

\author{
عاليه حسين نزاد 'Did)، مريم خدادادى 'Did)، نغين ناصح
}

جـ

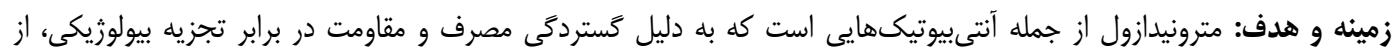

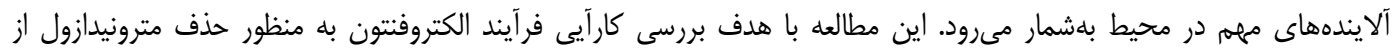

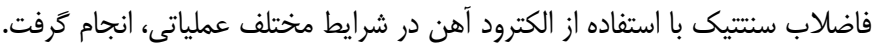

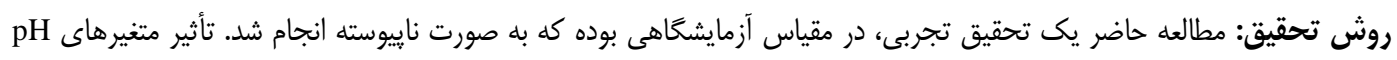

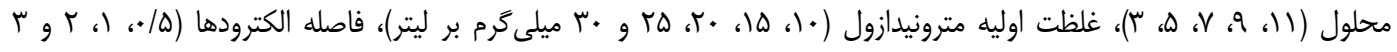

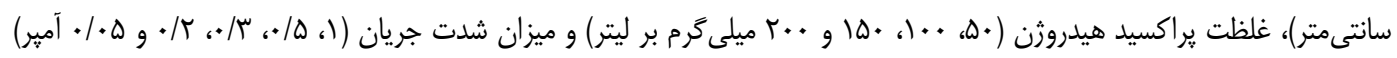

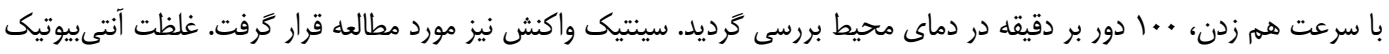

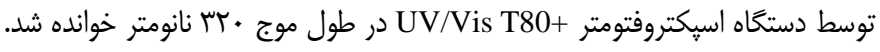

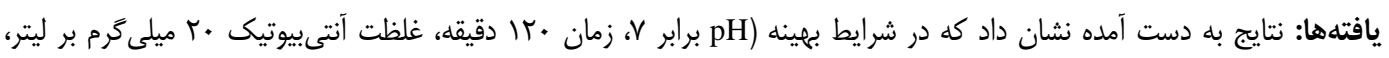

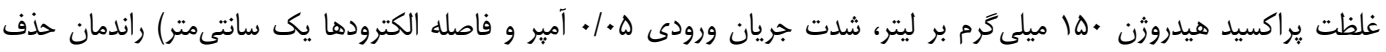

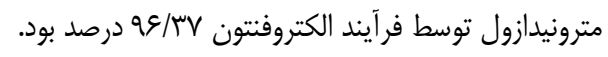

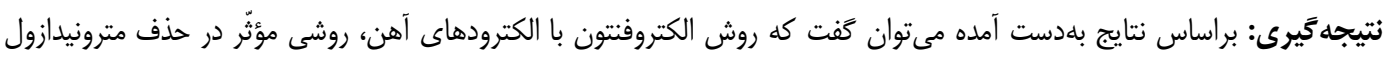
از محلولهاى آبى است.

$$
\begin{aligned}
& \text { وازههاى كليدى: آنتىبيوتيك؛ محلولهاى آبى؛ الكتروفنتون؛ الكترود آهن؛ مترونيدازول }
\end{aligned}
$$

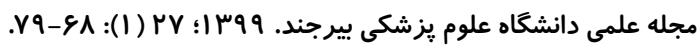

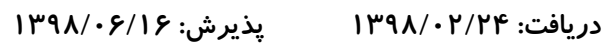

ب' كميته تحقيقات دانشجويى، دانشكاه علوم يزشكى بيرجند، بيرجند، ايران

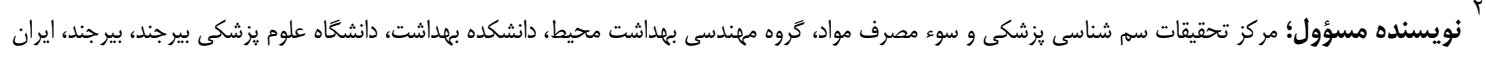

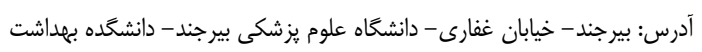

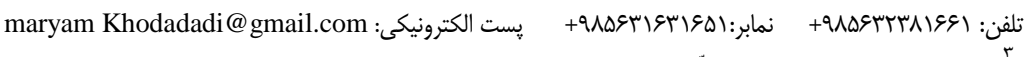
" مركز تحقيقات عوامل اجتماعى مؤثثر بر سلامت، كروه مهندسى بهداشت محيط، دانشكده بهداشت، دانشعاه علوم يزشكى بيرجند، بيرجند، ايران 
حذف مترونيدازول كزارش شده است؛ اما اين روشها در كنار مقدمه

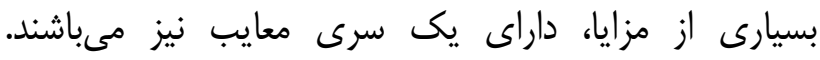

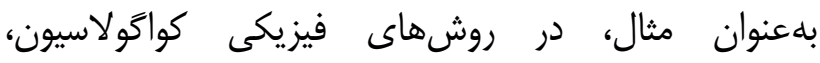

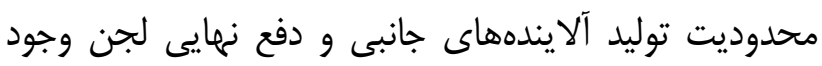

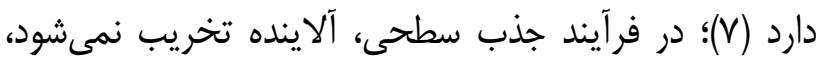

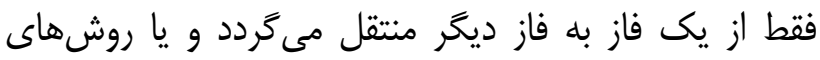

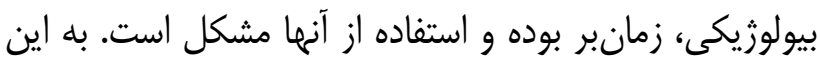
ترتيب با توجه به مطالعات بسيار، فرآيندهاى اكسيداسيون

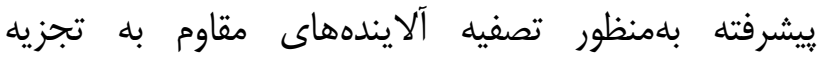
بيولوزيكى مانند آنتىييوتيكها، فرآيندهاى مناسبى هستند

فرآيندهاى اكسيداسيون بيشرفته (AOPs)'، بلهطور مرتب

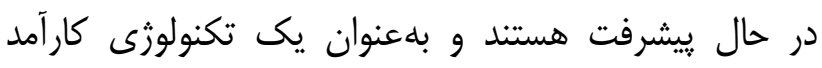

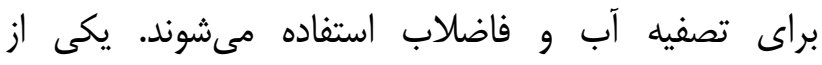

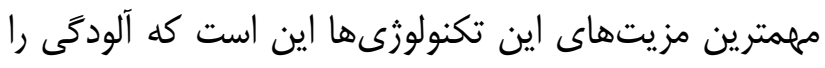

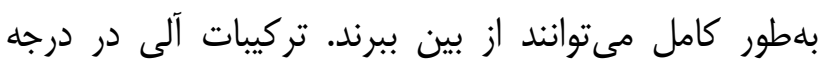

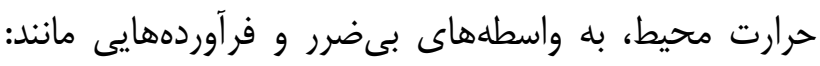

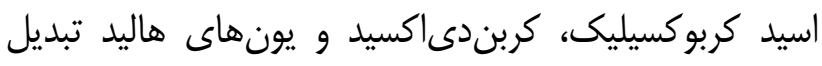

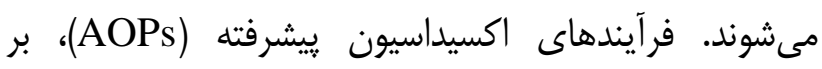
اساس توليد كونهاى فعال از جمله راديكال هاى هاى هيدروكسيل

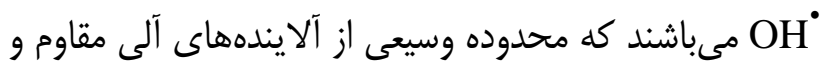

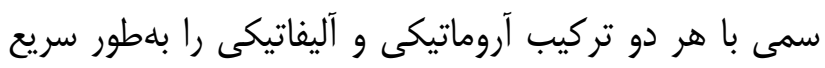

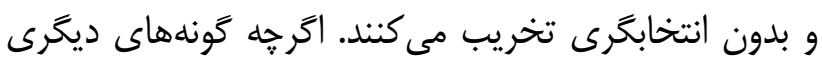

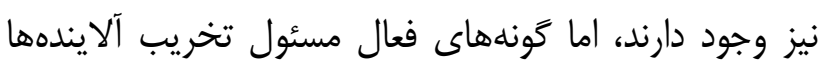

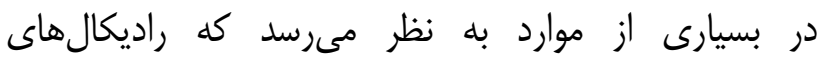

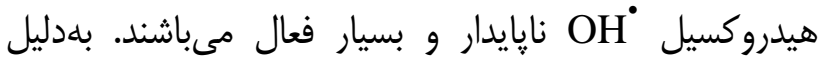

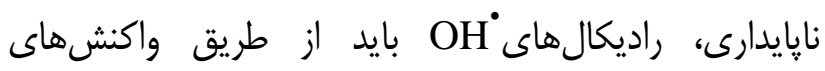

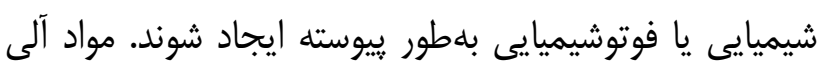

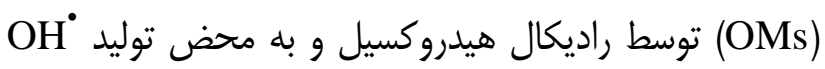
مورد حمله قرار مى گيرند:

$\mathrm{OM}+\mathrm{OH} \bullet \rightarrow$ حونهاى غير مضر $\rightarrow \mathrm{CO}_{2}, \mathrm{H}_{2} \mathrm{O}$

در دهلهاى اخير، حضور آلايندهاى با منشأ آلى در منابع

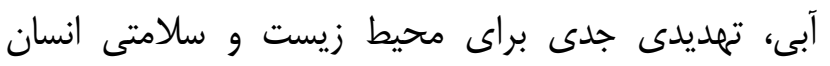

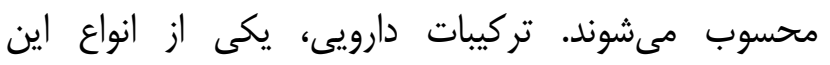

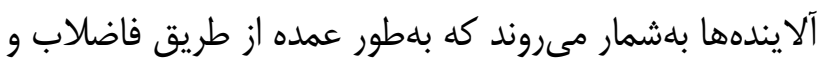

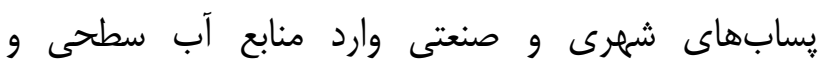

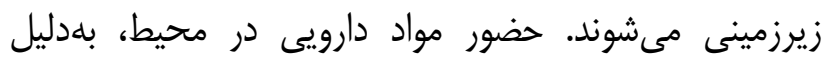

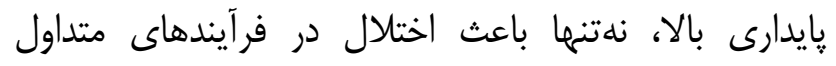
تصفيه فاضلاب در سيستمهاى تصفيه مىشوند، بلكه اثرات

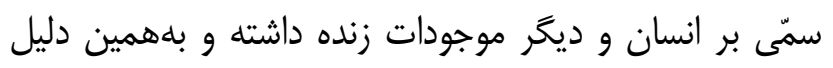

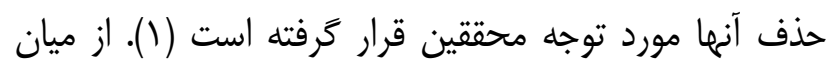

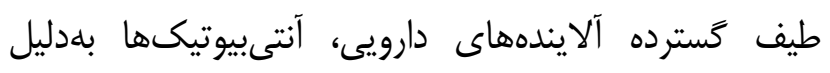

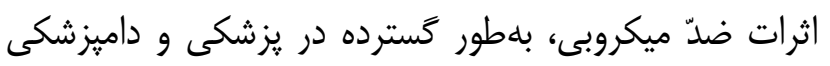

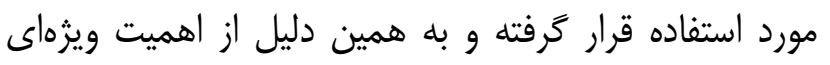

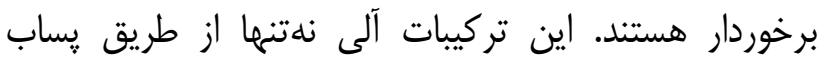

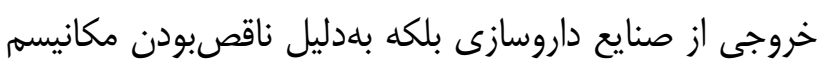

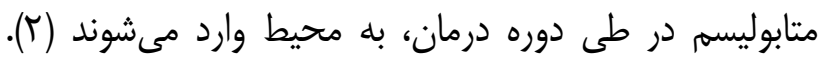

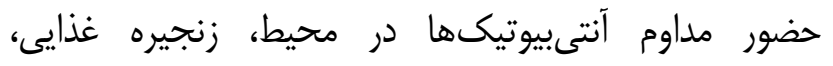

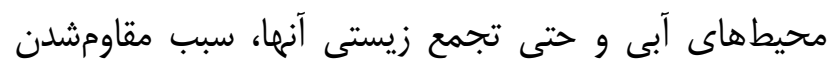

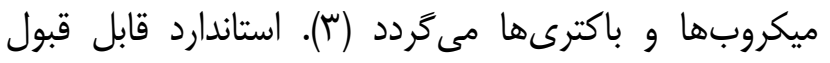

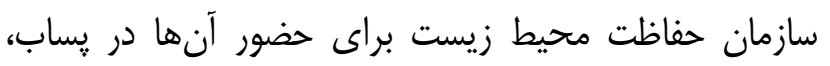
يك ميلى گرم در ليتر است (أ).

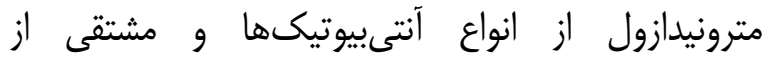

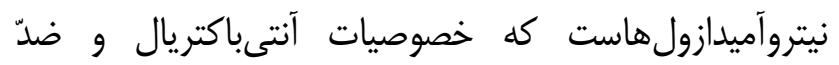

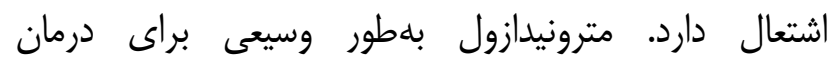

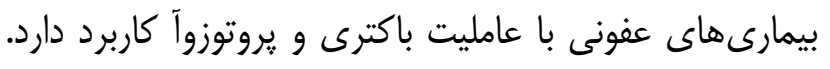

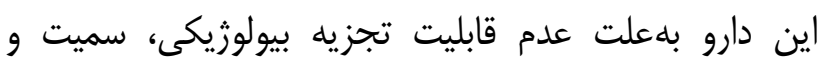

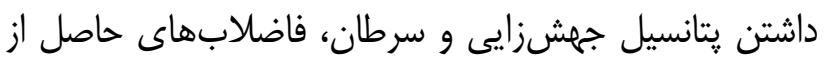

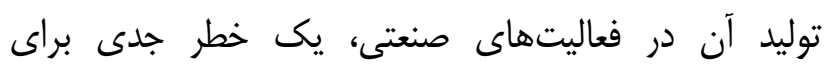

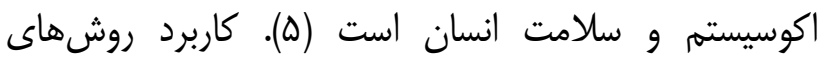

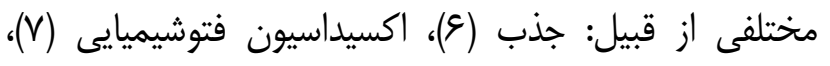

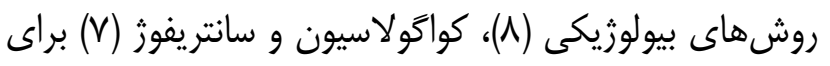




\section{تهيه محلول استوك:}

محلول استوى مترونيدازول، با حلنمول ملنون داروى

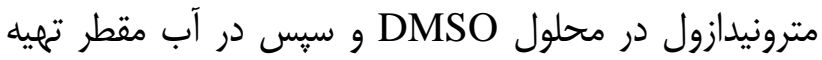

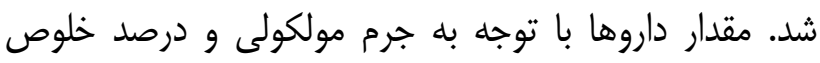

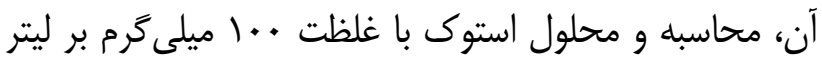
تهبيه گرديد.

\section{راكتور به كار رفته در مطالعه حاضر:}

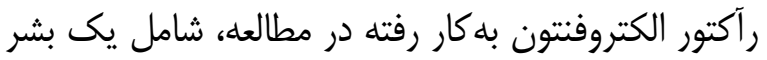

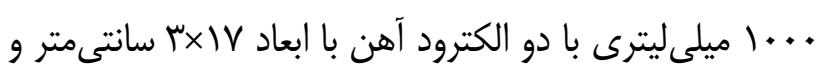
ضخامت يك ميلىمتر بود. الكترود مورد استفاده، بلهوسيله

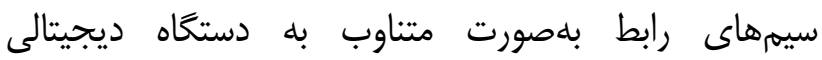

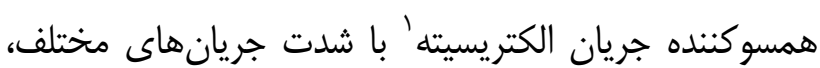

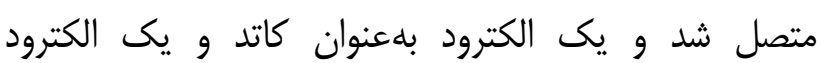
بلهنوان آند مورد استفاده قرار كرفت.

آزمايثهاى حذف مترونيدازول با استفاده از فرآيند

الكتروفنتون:

اين يزوهش، يك مطالعه تجربى آزمايشگاهى (كد اخلاق

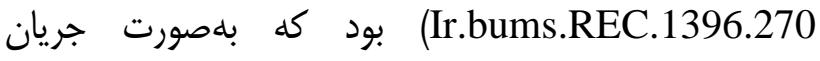

مستقيم توسط روش الكتروفنتون در حذف آنتىبيوتيك

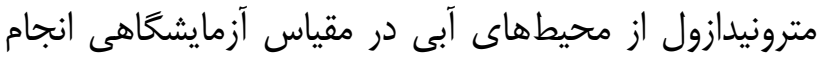

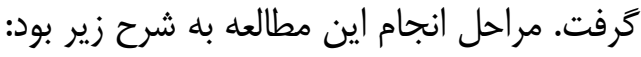

براى انجام آزمايشها ابتدا مقدار ـ ...

غلظت مشخص توسط بالون زوزه برداشته و داخل راكتور

ريخته شد و براى تنظيم pH، از

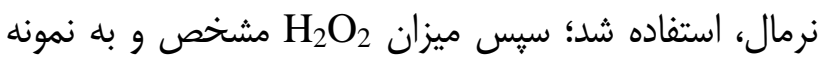

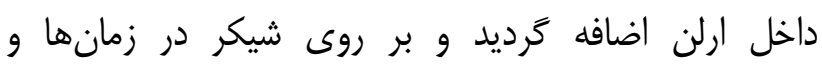

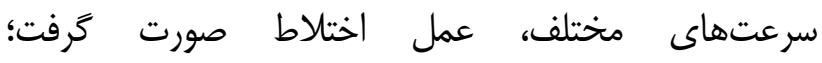

فر آيندهاى اكسيداسيون ييشرفتهاى كه در سالهاى اخير در تصفيه آب و انواع فاضلابها استفاده شدهاند شامل: ازن و

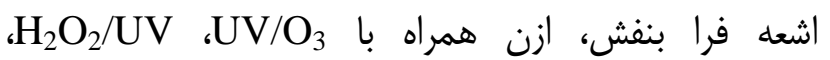
و فر آيند فنتون هستند (I) O $\mathrm{O}_{3} / \mathrm{H}_{2} \mathrm{O}_{2}$

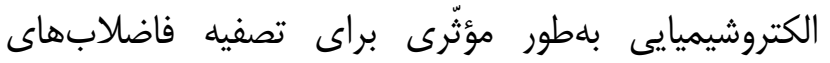

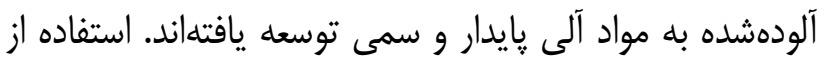

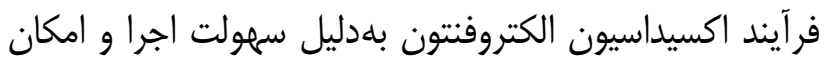
بهكارگيرى در مقياسهاى مختلف و ملاحظات اقتصادى،

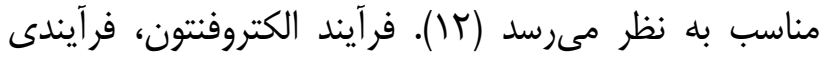

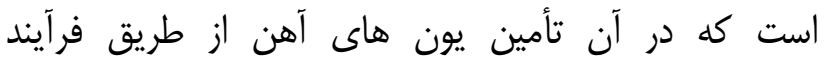
الكتروشيميايى امكانيذير است. در اين فرآيند، يونهاى آهن آهن

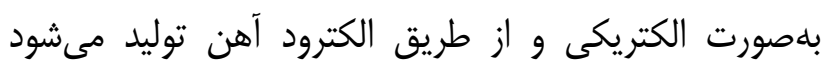

در فرآيند الكتروفنتون در حضور آهن دوظرفيتى كه از

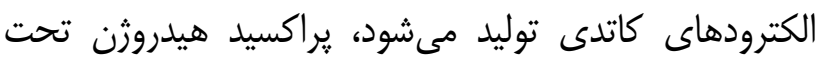

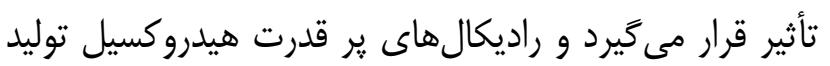

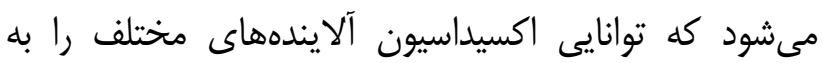

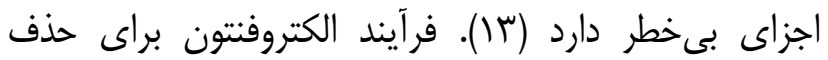

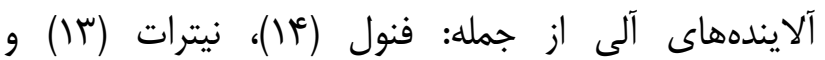

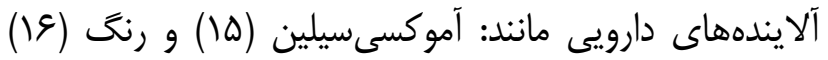

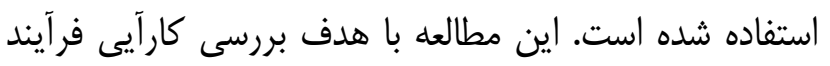

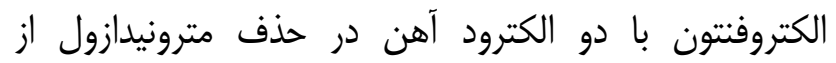
محيطهاى آبى انجام شد.

مواد شيميايى مورد استفاده در اين مطالعه شامل: يودر

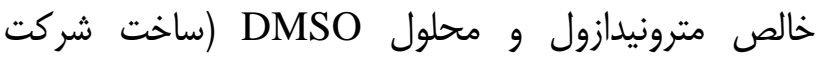
NaCL و HCL ، (ساخت شركت Merck آلمان) بود. خصوصيات مترونيدازول در جدول ا خزارش شده است.

\footnotetext{
${ }^{1}$ DC Supply Power
} 
جدول ا - خصوصيات فيزيكى و شيميايى مترونيدازول

\begin{tabular}{|c|c|c|c|c|c|}
\hline فرمول & $\begin{array}{c}\text { وزن مولكولى (gr/mol) } \\
\text { (gr/ol }\end{array}$ & آب (g/L اليت در & ساختار مولكولى & نام تجارى & \\
\hline $\mathrm{C}_{6} \mathrm{H}_{9} \mathrm{~N}_{3} \mathrm{O}_{3}$ & $|V| / \Delta$ & $9 / \Delta$ & & ا بتا هيدروكسى اتيل دو متيل -ه-- & \\
\hline
\end{tabular}

مترونيدازول و غلظت باقيمانده آلاينده، بر اساس مقالات

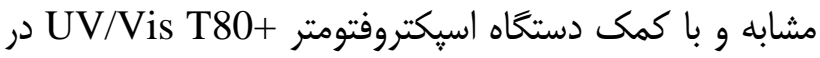

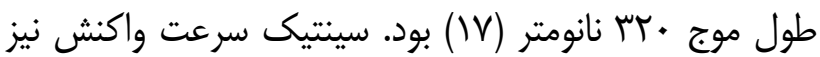
محاسبه شد.

\section{بافته ها}

$$
\text { بر برى اثر :pH }
$$

با توجه به نتايج حاصل از آزمايشها، راندمان حذف بر آن

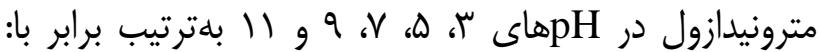

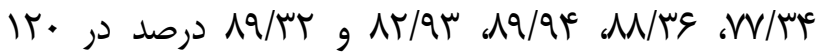

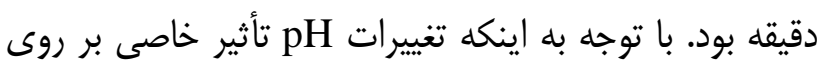

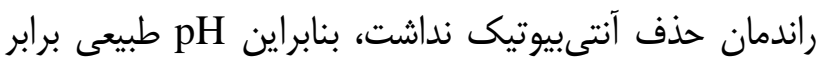
با V بلهنوان pH بهينه انتخاب شد (نمودار ( ).

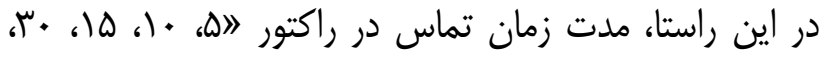

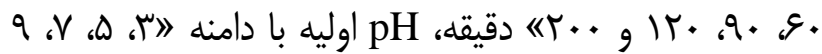

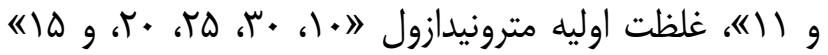

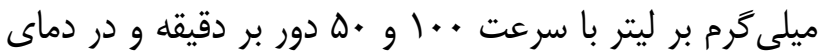
محيط و غلظت

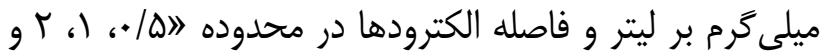

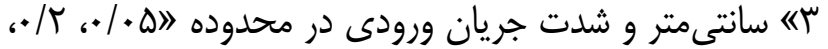

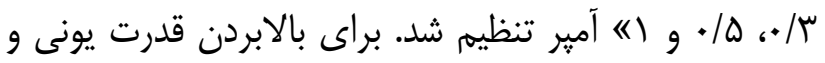
افزايش هدايت الكتريكى، محلول ماده الكتروليت كلريد سديه، به مقدار ثابت ه/ • گرم، به تمام نمونهها افزوده شده.

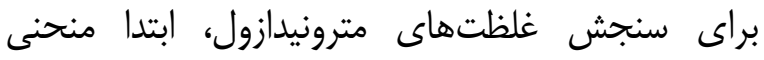
كاليبراسيون با غلظتهاى مختلفى از مترونيدازول رسم كرديد

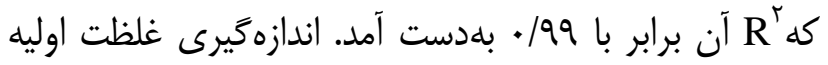

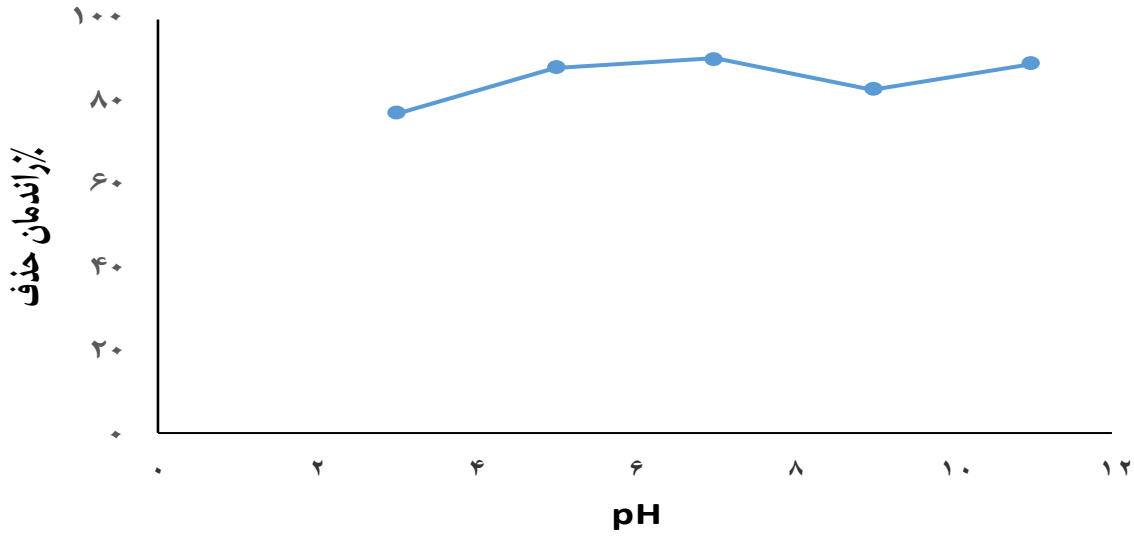

نمودار ا - بررسى تغييرات pH در كار آيى حذف آنتىبيوتيك مترونيدازول توسط فرآيند الكتروفنتون (فاصله الكترود=

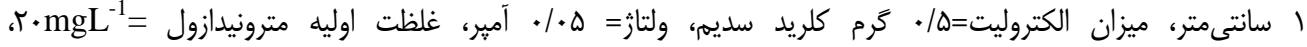

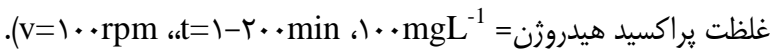




\section{بر بـى اثر سرعت اختلاط:}

نمودار ب نشان مىدهد كه همزدن سرعت محلول، تأثير مستقيم

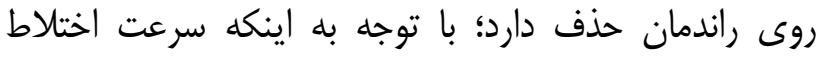

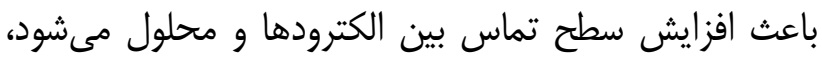

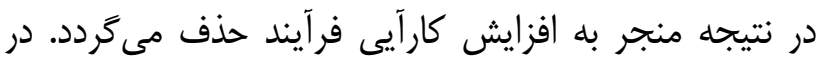

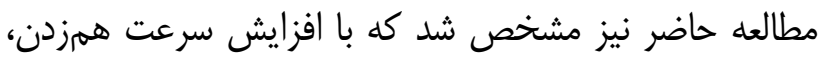

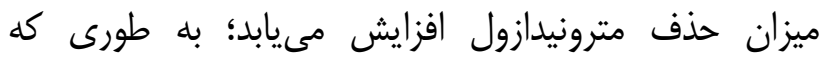

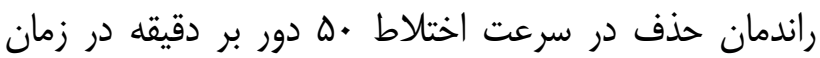

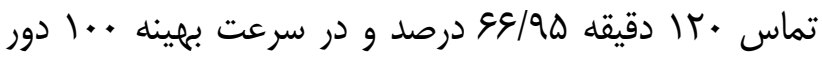

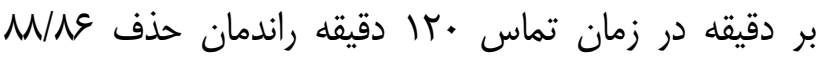

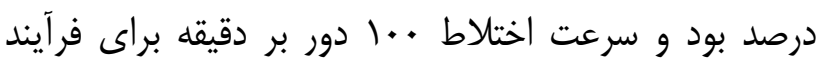
الكتروفنتون، بهينه كرديد.

\section{بر برى اثر زمان تماس و غلظت}

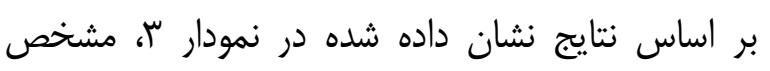

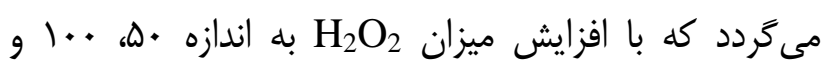

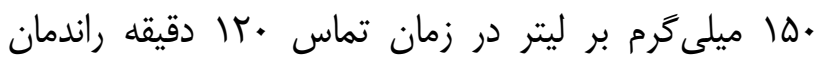

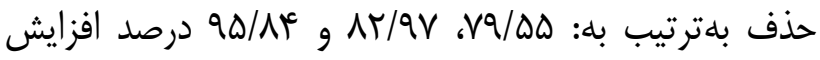

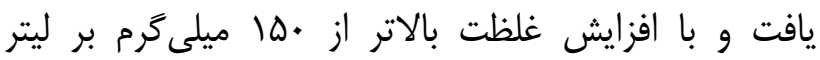

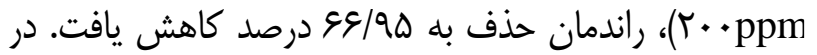
ن مرحله غلظت •ما ميلى

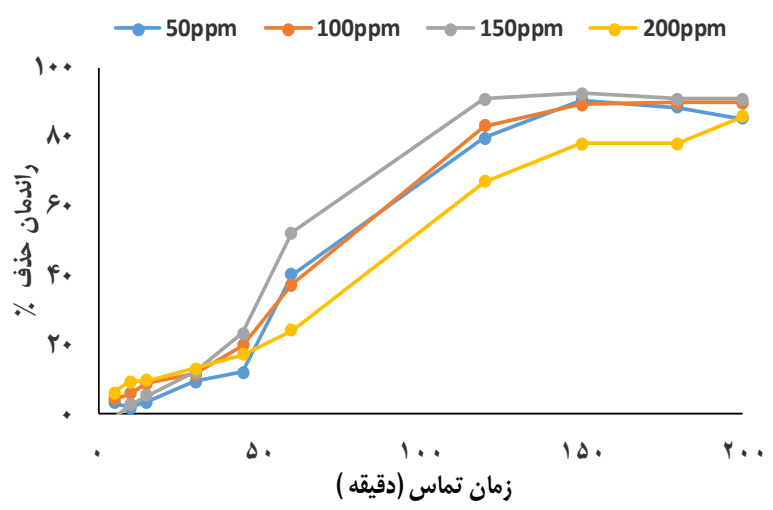

نمودار س- بروسى اثر غلظت مترونيدازول توسط فرآيند الكتروفنتون (غلظت اوليه مترونيدازول

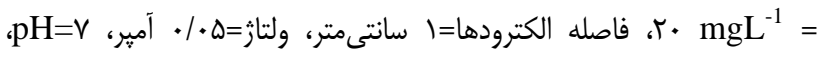
$(\mathrm{v}=1 \cdot \cdot \mathrm{rpm}$ : $\mathrm{t}=1-\mathrm{r} \cdot \cdot \mathrm{min}$

\section{بررسى اثر زمان تماس و غلظت اوليه آنتىبيوتيك} مترونيدازول: در مطالعه حاضر براى بررسى غلظت آنتىبيوتيك، از

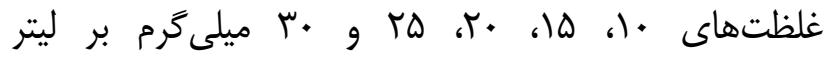
مترونيدازول استفاده شد. بر اساس نتايج نشان داده شده در

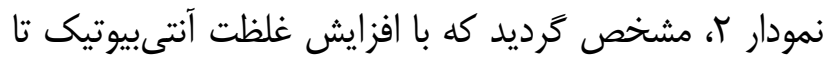

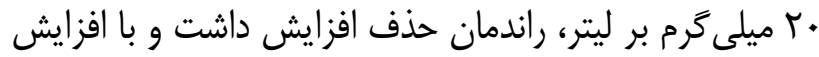

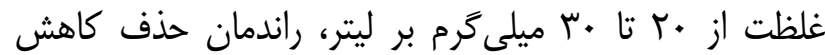

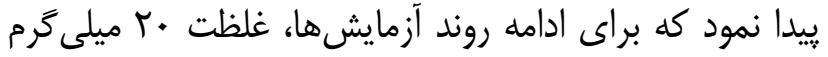

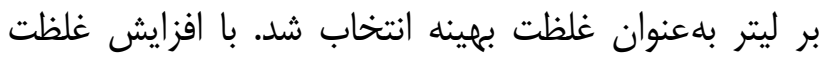

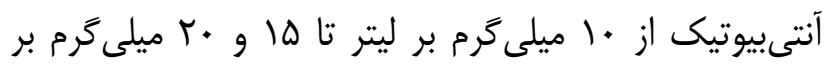

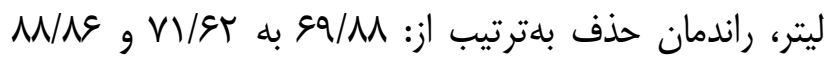

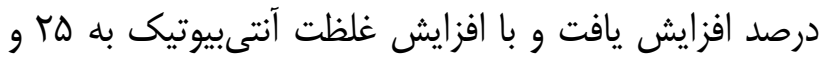

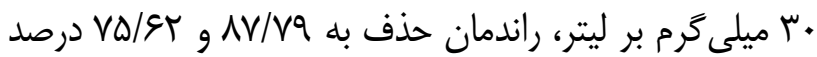

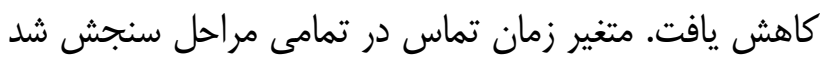

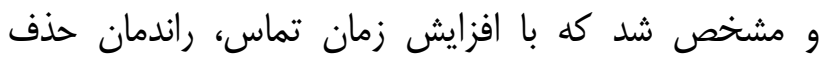

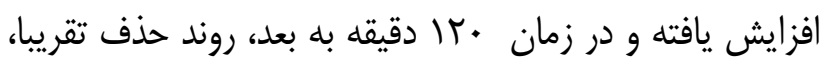

$$
\text { ثابت گرديد. }
$$

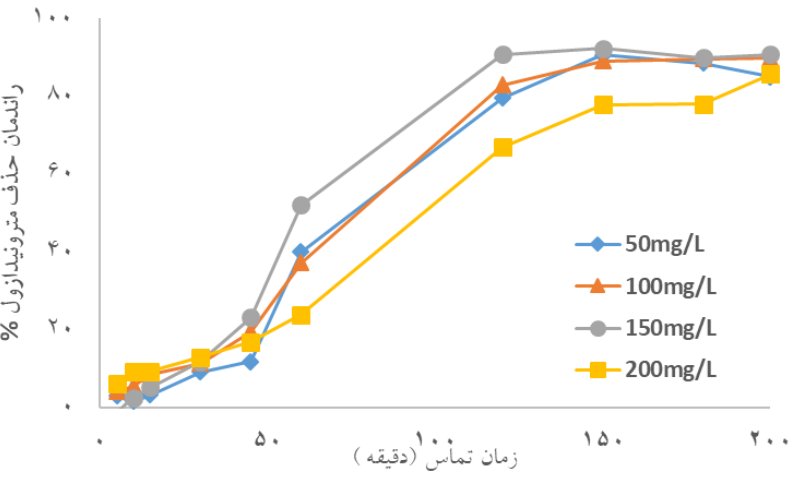

نمودار r- بررسى اثر غلظت آنتىبيوتيك در كارآيى حذف آنتىبيوتيك

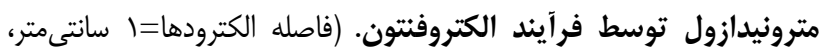

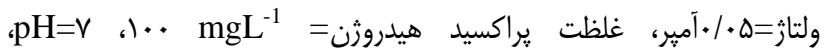
$(\mathrm{v}=) \cdot \cdot \mathrm{rpm}$ ، $\mathrm{t}=)-\mathrm{r} \cdot \cdot \min$ 


\section{بر رسى اثر فاصله الكترودها:}

بر اساس نتايج نشان داده شده در نمودار هـ مشاه مشخص

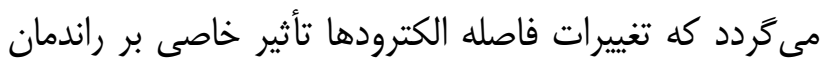

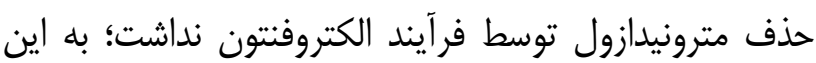

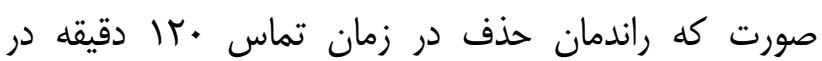

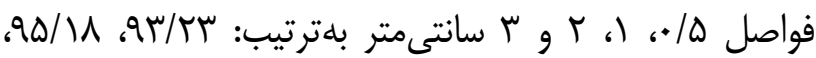

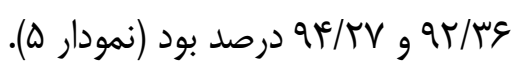

\section{مطالعه سينتيك حذف:}

سينتيكهاى شيميايى نشاندهنده سرعت واكنش هاى ماى

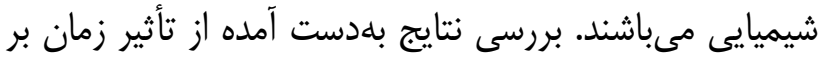

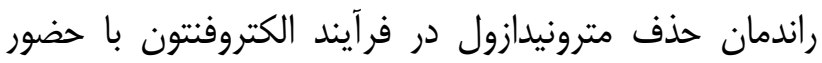
مقادير مناسب متغيرها مطابق جدول r ب و نمودار

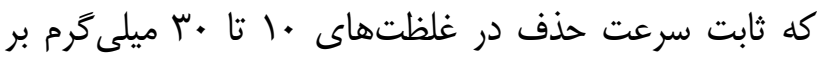

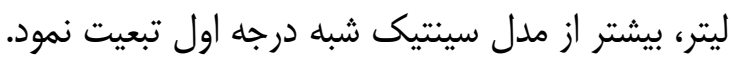

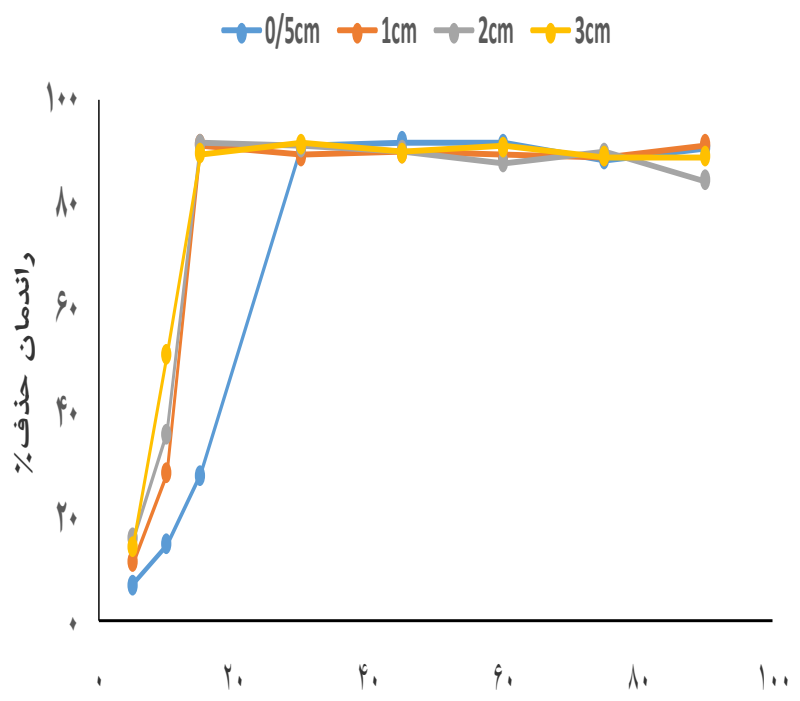

نمودار ه- بررسى اثر فاصله الكترودها در كارآيى حذف فئن

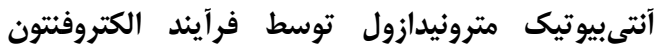

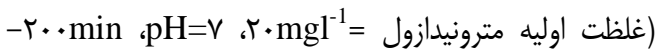

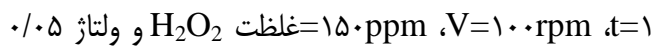

\section{بررسى اثر اختلاف يتانسيل الكتريكى:}

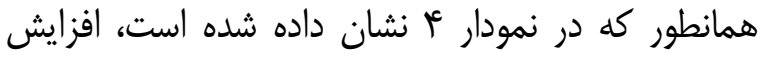

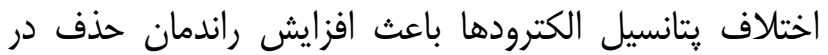

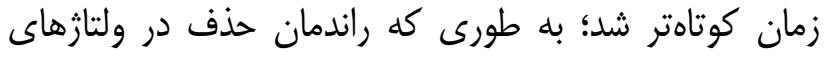
ه•/

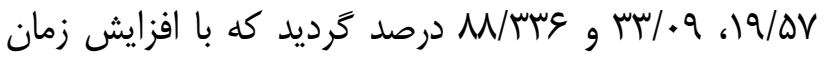
تماس راندمان حذف افزايش يافت و راندمان حذف بلهترتيب

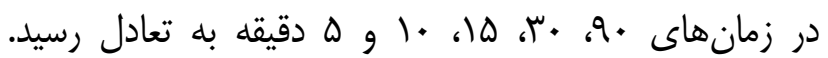

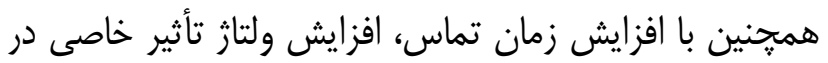

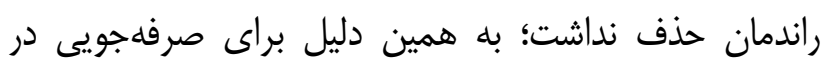

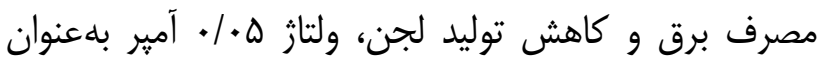
ولتاز بهينه انتخاب گرديد (نمودار عأ).

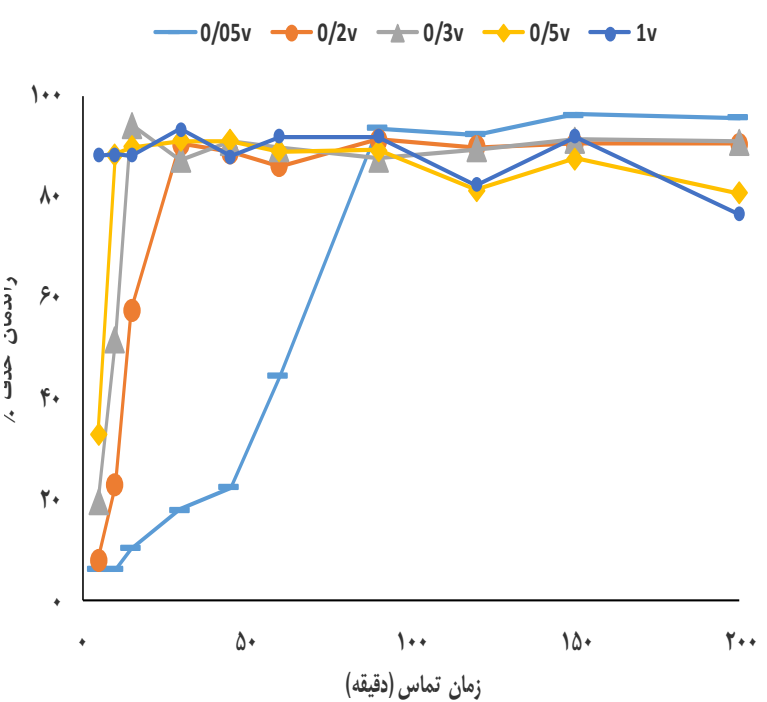

نمودار f أf- بررسى اختلاف يتانسيل در كارآيى حذف فئن

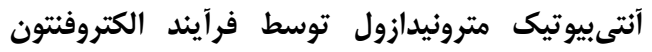

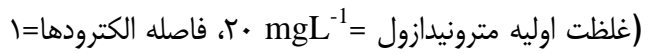
سانتىمتر، ،

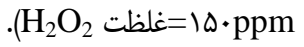




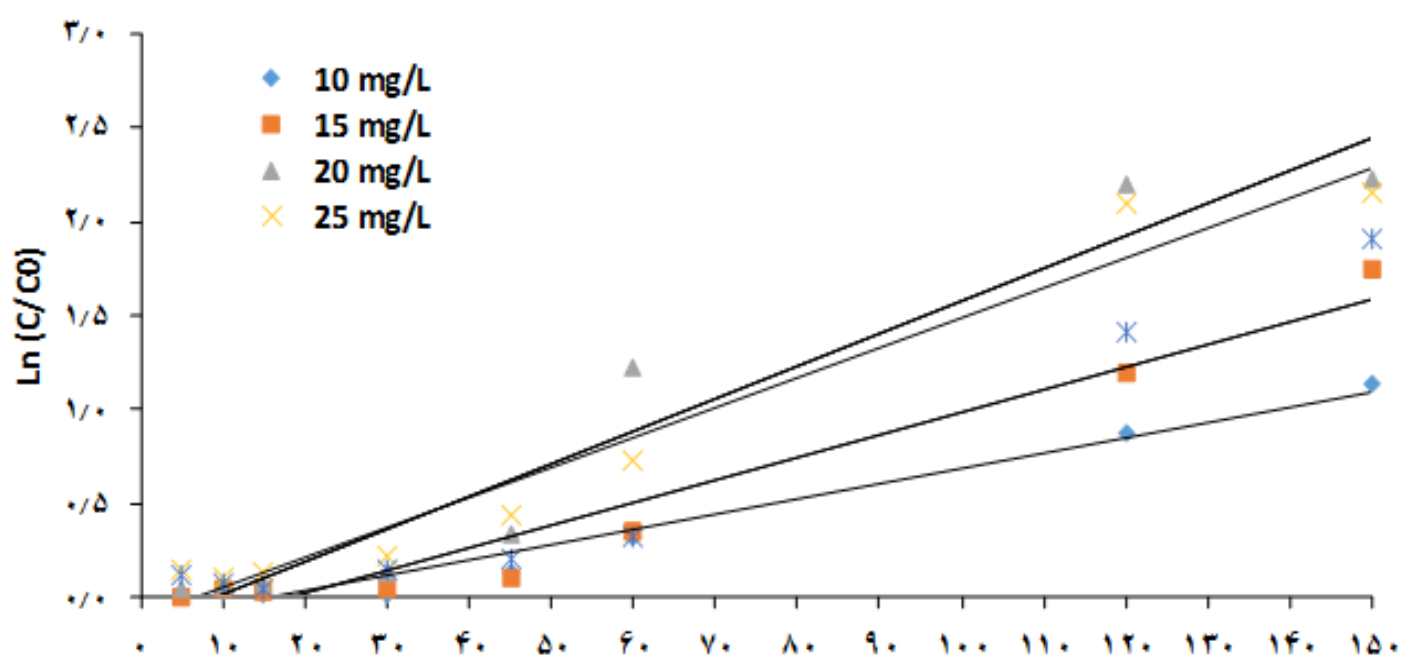

Time (min)

نمودار צ- سينتيك حذف مترونيدازول در فرآيند الكتروفتتون (فاصله الكترودها=| سانتىمتر، ولتاز=ه•|•آمبر، غلظت مترونيدازول=

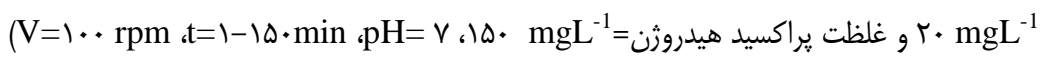

جدول ץ- نتايج حاصل از برازش دادههاى تعادلى براى تعيين سينتيك فرآيند الكتروفنتون در حذف مترونيدازول

\begin{tabular}{|c|c|c|c|c|}
\hline $\begin{array}{c}\text { Concentration } \\
(\mathrm{mg} / \mathrm{L})\end{array}$ & Equation & $K_{0}\left(\min ^{-1}\right)$ & $\mathbf{R}^{2}$ & $\mathbf{t}_{1 / 2}(\min )$ \\
\hline 1 & $Y=\cdot / \cdot \cdot \wedge r X-1 r / \cdot 1$ & $N / r \times)^{-r}$ &.$/ 971$ & $\Lambda F / \Delta 1$ \\
\hline 10 & $\mathrm{Y}=\cdot / \cdot|r \mathrm{X}-\cdot / 4| \mathrm{H}$ & $|r x| \cdot{ }^{-r}$ & . /9peq & $\Delta V / V Q$ \\
\hline$r$. & $\mathrm{Y}=\cdot / \cdot \mid V^{c} \mathrm{x}-\cdot / 1 \varepsilon \mathrm{g}$ & $\left|V / \mathbb{F}^{c} \times\right| \cdot{ }^{-\mu}$ &.$/ 94 \cdot 1$ & rq/ır \\
\hline ro & $Y=\cdot 1 \cdot 19 x-\cdot / 11 V^{2}$ & $|\varepsilon \times| \cdot \cdot^{-r}$ &.$/ 9811$ & ( \\
\hline r. & $\mathrm{Y}=\cdot / \cdot 1 \mathrm{r}^{\prime} \mathrm{X}-\cdot / 11 \wedge \varepsilon$ & $\mid r / 9 \times 1 \cdot^{-r}$ & . & $\Delta r / V r$ \\
\hline
\end{tabular}

مترونيدازول را نشان مىدهد. با توجه به نتايج آزمايشهاى مختلف و بررسى گارامترهاى گَوناگون در مطالعه حاضر، نتايج فرآيند الكتروفنتون بلددليل سادگى، عدم نياز به تجهيزات

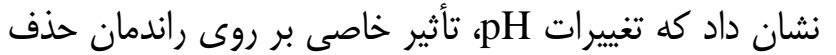

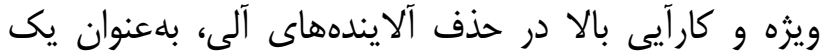

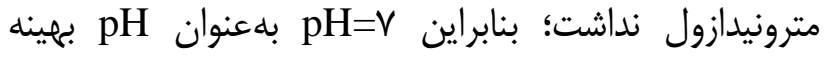
جايخزين عالى براى تخريب و تجزيه آلايندههاى مقاوم و وانى

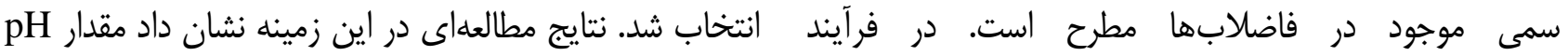
محلول، بلهور مستقيم بر روى غلظت هيدروثن مثبت و يون

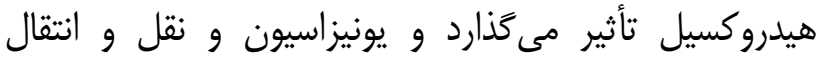

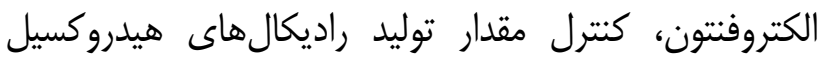

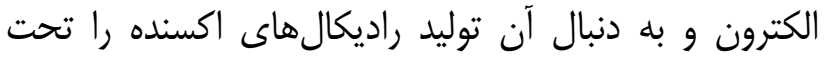
بهتر صورت مى گيرد؛ در اين فر آيند، محصولات نهايى ناشى مئى

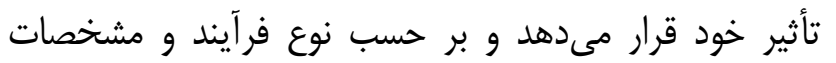

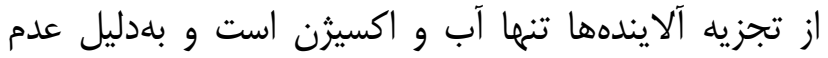
محلول داخل راكتور، شدت نقل و انتقال و توليد راديكال در

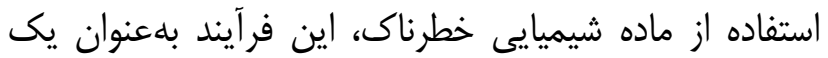
عامل سبز و دوستدار محيط زيست شناخته شده است (عادئ (1).

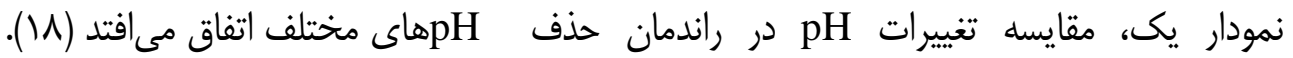


هيدروكسيل در محيط افزايش و بنابراين بازده فرآيند، بهبود

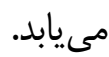
نرخ حذف از شروع تا انتهاى آزمايشها در نمودار سانشان

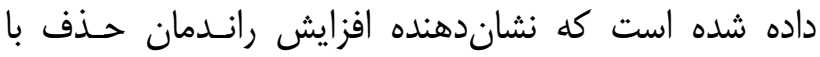

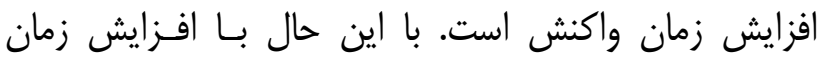
واكنش، نرخ و شيب حذف مترونيدازول كمتـر شــده است.

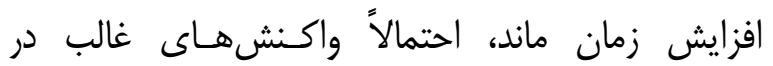

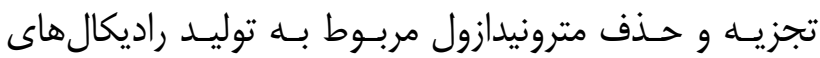
هيدروكسيل طى واكنش يك را ترغيب نموده كه بدون توليد

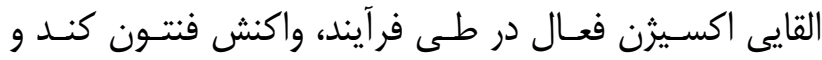

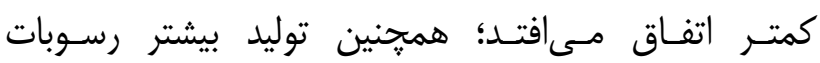
Fe(OH)3 در محلول در زمان هاى ماند بالاتر، علت احتمالى مولى ديخرى مىباشد (1ه). در فرآيند الكتروفنتون، راديكالهاى هيدروكسيل مالث مطابق

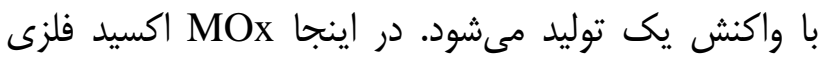

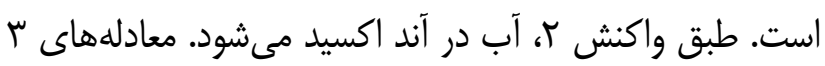
و ع نيز واكنشهاى كاتدى را نشان مى لدهند.

\section{Anode:}

( ) $\mathrm{MO}_{\mathrm{x}}+\mathrm{H}_{2} \mathrm{O} \longleftrightarrow \mathrm{MO}_{\mathrm{x}}\left(\mathrm{OH}^{0}\right)+\mathrm{H}^{+}+\mathrm{e}$

(r) $\mathrm{H}_{2} \mathrm{O} \longleftrightarrow \mathrm{O}_{2}+4 \mathrm{H}^{+}+4 \mathrm{e}$

\section{Cathode:}

(r) $\mathrm{H}_{2} \mathrm{O}+\mathrm{e} \longleftrightarrow \mathrm{H}_{2}+2 \mathrm{OH}^{-}$

(i) $\mathrm{O}_{2}+2 \mathrm{H}^{+}+2 \mathrm{e} \longleftrightarrow \mathrm{H}_{2} \mathrm{O}_{2}$

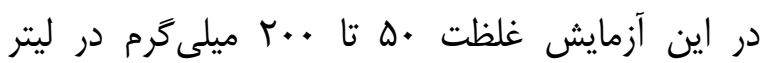
$\mathrm{H}_{2} \mathrm{O}_{2}$

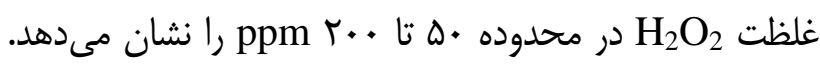

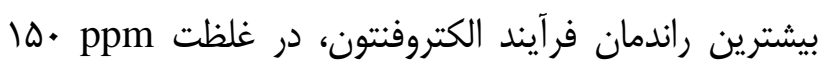

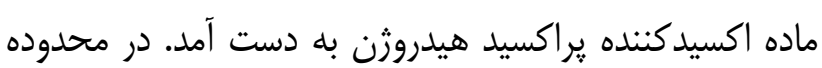

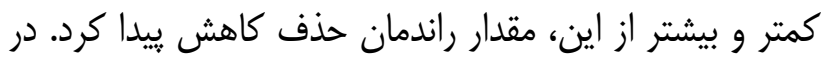

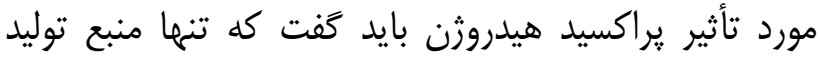
در فرآيند فنتون و الكتروفنتون، يراكسيد هيدروزن است. اين ماده يا بلصورت دستى به راكتور اضافه مىشود و
در مطالعات انجامشده، حذف آنتىييوتيكها و آلايندهاى آلى توسط فرآيند الكتروفنتون، در تمامى داى اسيدى،

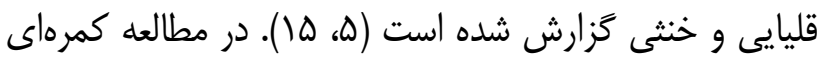

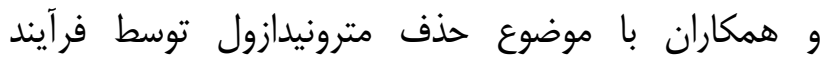
الكتروفنتون با استفاده از الكترودهاى آهن و كرافرافيت، مشابيه

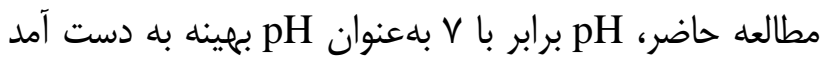

نمودار r، مقايسه تغييرات غلظت مترونيدازول در راندمان

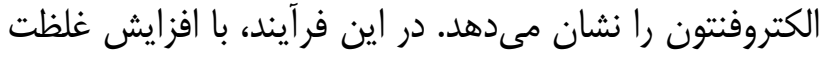

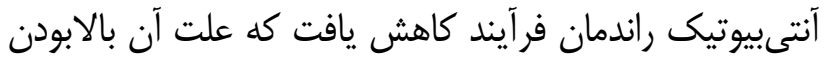
غلظت ماده آلى در محيط است كه موجب مصرف بيشت بيشتر ماده

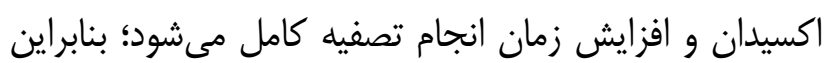

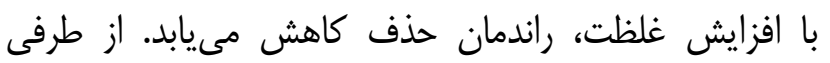

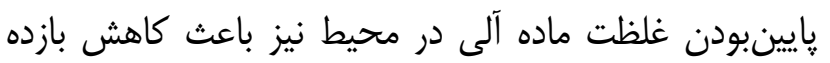

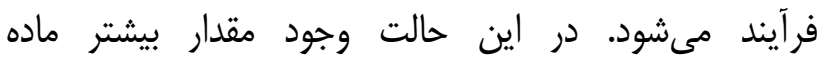

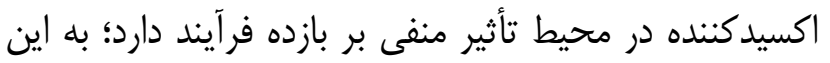

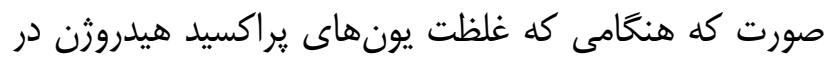

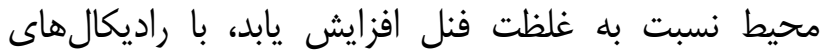

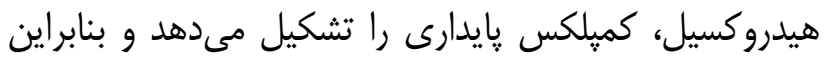

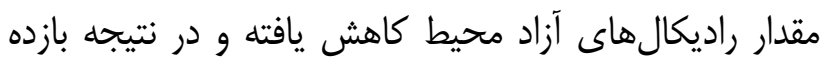

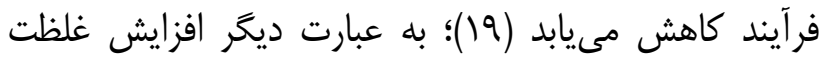

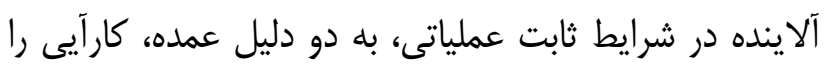
كاهش مىدهد و در مقدار ثابت OH

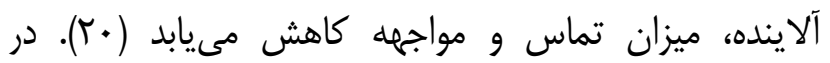

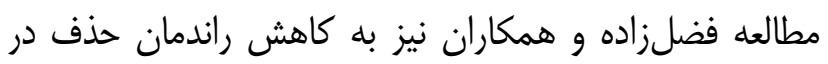

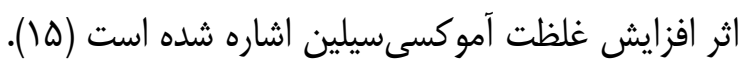
زمان واكنش، يكى از عوامل مؤثّر در انجام فر آيندهاى

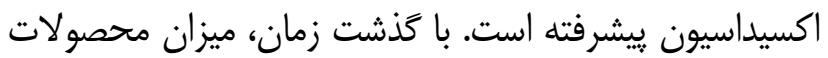

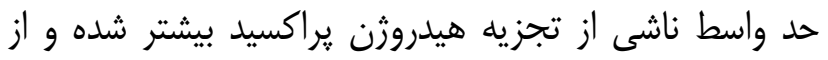

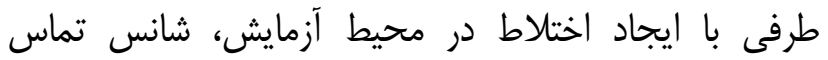

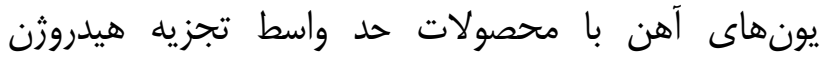
يراكسيد افزايش مىيابد و در نهايت محهولات روند توليد راديكال 
افزايش جريان الكتريكى، راندمان حذف افزايش و با افزايش

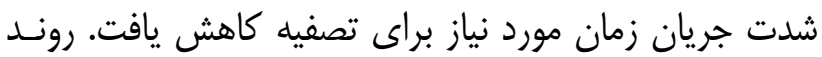

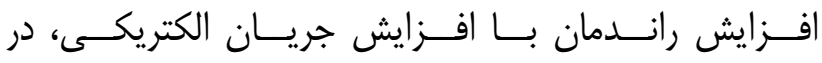

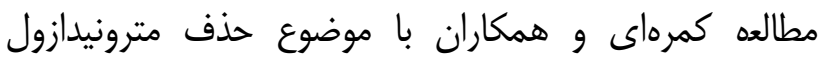

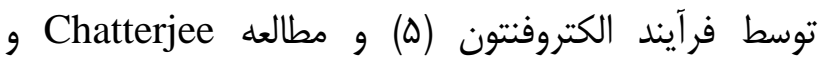
همكاران با موضوع حذف آموكسىسيلين نيز مشاهده كرديد

همانطور كه در نمودار ه نشان داده شده است، تغييرات

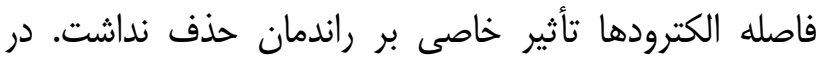

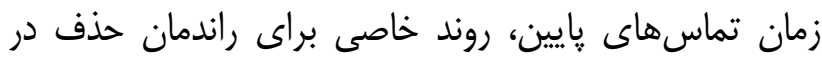

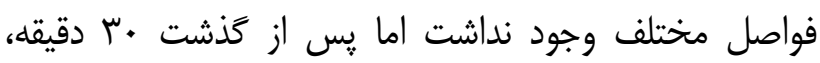

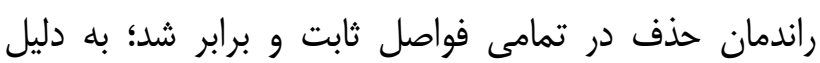

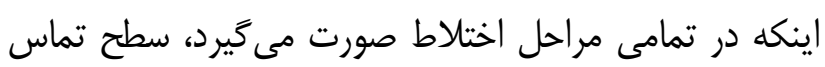
محلول و الكترود در تمامى فواصل يكسان مى مباشد.

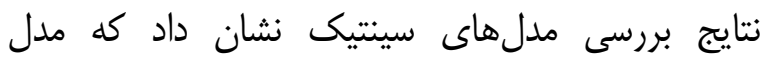

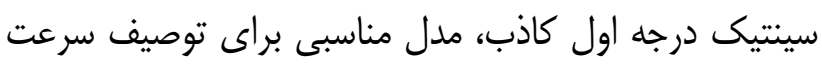

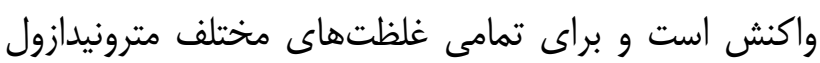

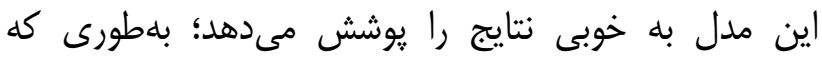

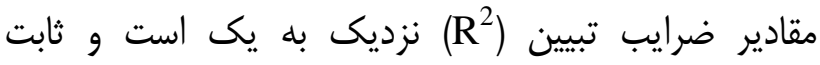
سرعت واكنش با افزايش غلظت آنتى بيوتيك كاهش مي ميابد.

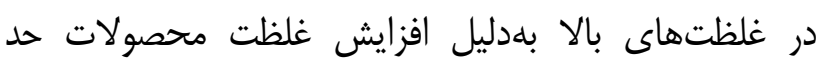
واسط، تعداد راديكالهاى هيدروكسيل فعال در واكنش، دالئ

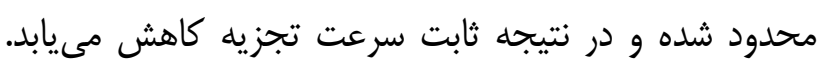

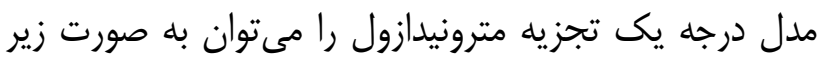
معادله يك بيان كرد (ז (T).

$$
-\ln (\mathrm{C} / \mathrm{C} 0)=\mathrm{K}_{\text {overall }} \cdot \mathrm{t}
$$

معادله (1):

كه در اين فرمول Koverall عبارت است از ثابت سرعت

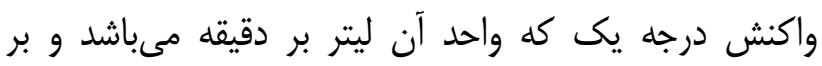

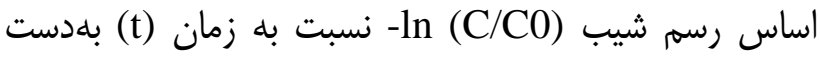

همانطور كه نتايج حاصل از بررسى كينتيك واكنشها در نمودار \& نشان داد، ثابت سرعت واكنش در در فر فرآيند
يا از طريق انتشار اكسيرن در سطح كاتد توليد مىشود.

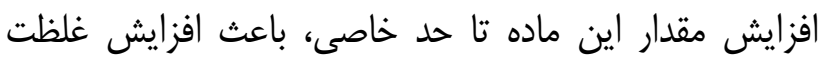

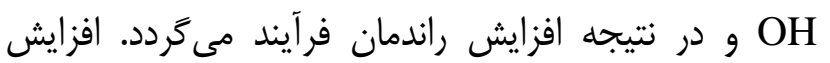

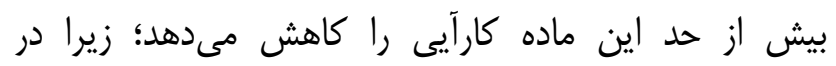

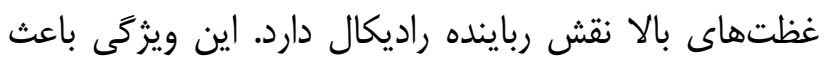

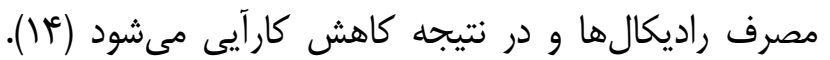

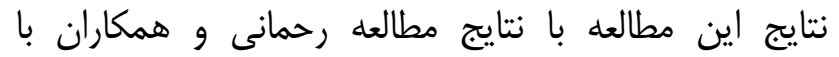
موضوع حذف فنول توسط فرآيند الكتروفنتون همخوانى دارئ دارد

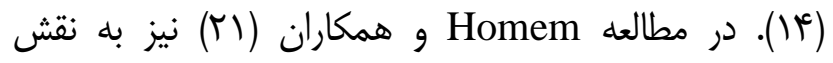

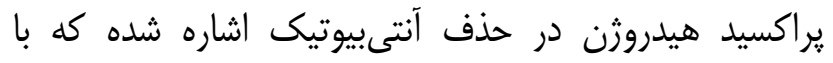

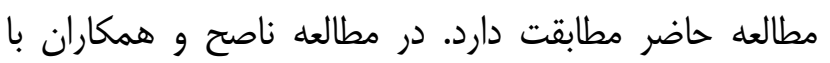
موضوع حذف مترونيدازول توسط فرآيند شبه فنتون توسط داري

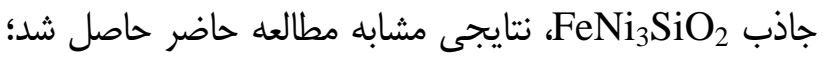
بدين صورت كه با افزايش غلظت

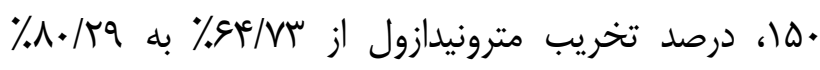

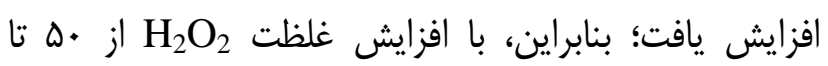

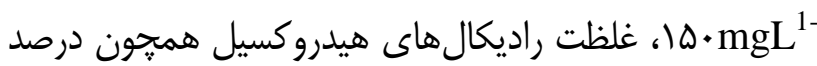
حذف مترونيدازول افزايش مىيابد. با توجه باديه ريزايل

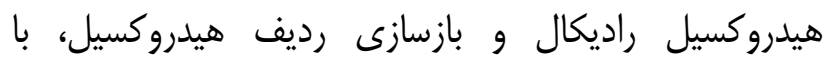
افزايش غلظت

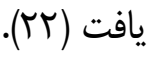
يكى از فاكتورهاى مهم ديخرى كه بر كارآيى فرآيند

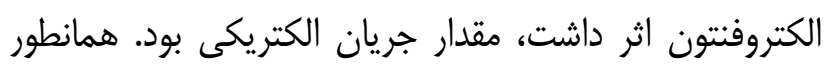

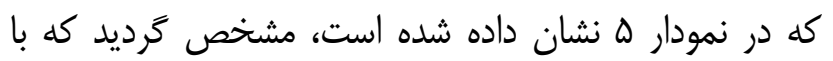

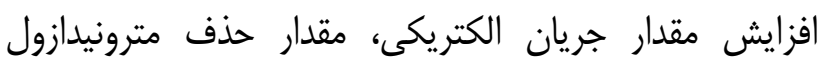
افزايش يافت. علت راندمان بالاى حذف آلايندهها با افزايش إناف

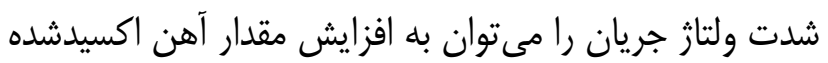

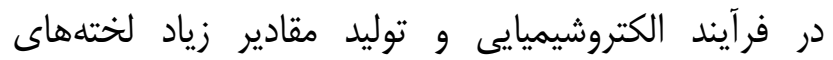
تهنشينشونده هيدروكسيد همجينين با افزايش دانسيته جريان، ميزان توليد و قدرت

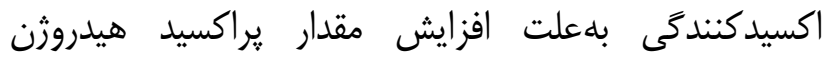
توليدشده در كاتد افزايش مىيابد (ه). در مطالعه حاضر با فيا 


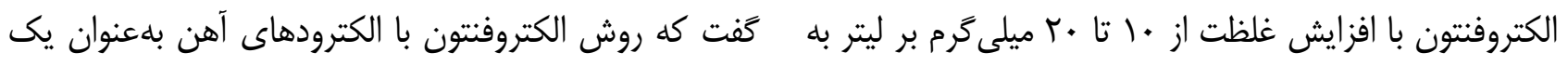

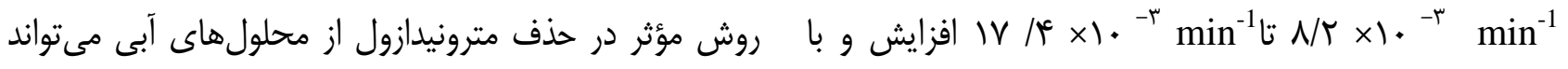

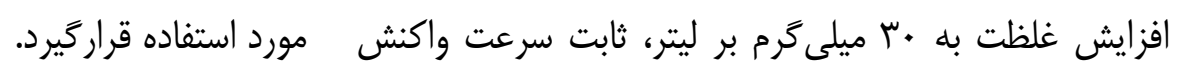

$$
\begin{aligned}
& \text { به به } \\
& \text { تقدير و تشكر }
\end{aligned}
$$

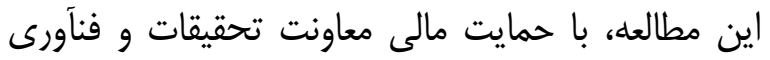

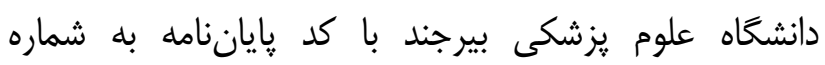

$$
\begin{aligned}
& \text {. } \\
& \text { همكارى آن معاونت كمال تشكر را دارند. } \\
& \text { تضاد منافع } \\
& \text { نتايج حاصل از مطالعه حاضر نشان داد كه فر آيند } \\
& \text { الكتروفنتون، قادر به حذف مقادير بالايى از آنتىبيوتيك حاضيك }
\end{aligned}
$$

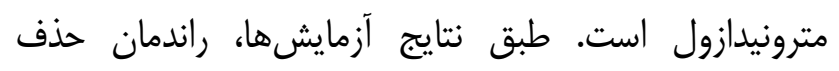

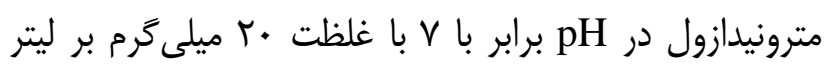

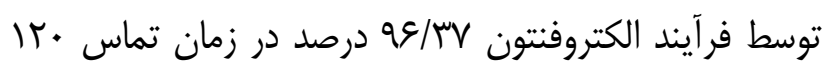

$$
\begin{aligned}
& \text { نويسندگان مقاله اعلام مىدارند كه هيج مونه تضاد }
\end{aligned}
$$

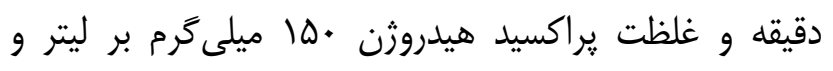

$$
\begin{aligned}
& \text { منافعى در ثيزوهش حاضر وجود ندارد. }
\end{aligned}
$$

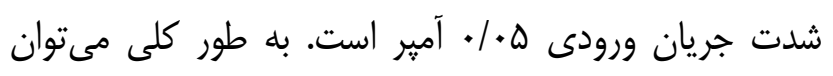

1- Dong H, Yuan X, Wang W, Qiang Z. Occurrence and removal of antibiotics in ecological and conventional wastewater treatment processes: A field study. J Environ Manage. 2016; 178: 11-9. doi: 10.1016/j.jenvman.2016.04.037

2- Seid Mohammadi A. Asgari Gh, Torabi L. Removal of Metronidazole using ozone activated persulfate from aqua solutions in presence of ultrasound. J Mazandaran Univ Med Sci, 2016; 26(143): 160-73. [Persian]

3- Seifrtov M, Novov L, Linob C, Penab A, Solicha P. An overview of analytical methodologies for the determination of antibiotics in environmental waters. Anal Chim Acta. 2009; 649(2): 58-79.

4- Vieno NM, Tuhkanen T, Kronberg L. Analysis of neutral and basic pharmaceuticals in sewage treatment plants and in recipient rivers using solid phase extraction and liquid chromatography-tandem mass spectrometry detection. J Chromatogr A. 2006; 1134(1-2): 101-11. doi: 10.1016/j.chroma.2006.08.077

5- Kamarehie B, Jafari A, Heydari R, Abbariki Ali. Study of the removal of metronidazole from aqueous solutions using Electro/Fenton process and graphite and iron electrodes. Yafte. 2018; 20(1): 41-51. [Persian]

6- Dantasa RF, Rossiterb O, RibeiroTeixeiraa AK, S.M.Simõesc A, Linsda da Silva VL. Direct UV photolysis of propranolol and metronidazole in aqueous solution. Chem Eng J. 2010; 158(2): 143-7. doi: doi.org/10.1016/j.cej.2009.12.017

7- Wang H, Zhang G, Gao Y. Photocatalytic degradation of metronidazole in aqueous solution by niobate K $6 \mathrm{Nb} 10.8$ O 30. Wuhan University Journal of Natural Sciences. 2010; 15(4): 345-9. doi: 10.1007/s11859-010-0664-0

8- Ingersleva F, Torängb L, Lokea ML, Halling-Sørensena B, Nyholmb N. Primary biodegradation of veterinary antibiotics in aerobic and anaerobic surface water simulation systems. Chemosphere. 2001; 44(4): 865-72. doi: 10.1016/S0045-6535(00)00479-3

9- Michael I, Hapeshi E, Michael C, Varela AR, Kyriakou S, Manaia CM, et al. Solar photo-Fenton process on the abatement of antibiotics at a pilot scale: degradation kinetics, ecotoxicity and phytotoxicity assessment and removal of antibiotic resistant enterococci. Water Res. 2012; 46(17): 5621-34. doi: 10.1016/j.watres.2012.07.049.

10- Yazdanbakhsh AR, Manshouri M, Sheikhmohammadi A, Sardar M investigation the efficiency of combined coagulation and advanced oxidation by Fenton process in the removal of Clarithromycin antibiotic cod. Water and Wastewater. 2012; 23(2): 22-9. [Persian] 
11- Murray CA, Parsons SA. Advanced oxidation processes: flowsheet options for bulk natural organic matter removal. Water Sci Technol Water Supply. 2004; 4(4): 113-9. doi: 10.2166/ws.2004.0068

12- Hu CY, Lo SL, Kuan WH. High concentration of arsenate removal by electrocoagulation with calcium. Sep Purif Technol. 2014; 126: 7-14.

13- Seid Mohammadi A, Mehralipour J, Shabanlo A, Roshanaie G, Barafrashtepour M, Asgari G. Comparing the Electrocoagulation and Electro-Fenton Processes for Removing Nitrate in Aqueous Solution for Fe Electrodes. J Mazandaran Univ Med Sci. 2013; 23(104): 57-67. [Persian]

14- Rahmani AR, Rezaeivahidian H, Almasi M, Shabanlo A Almasi H. A comparative study on the removal of phenol from aqueous solutions by electro-Fenton and electro-persulfate processes using iron electrodes. Res Chem Intermediat. 2016; 42(2): 1441-50.

15- Fazlzadeh M, Gulshan S, Bohloul A, Rezaei M. Evaluation of Electro-Fenton Process in Amoxicillin Removal from Aqueous Solutions. J Health. 2016; 7(3): 276-87. [Persian]

16- Malakootian M, Asadi M, Mahvi AH. Evaluation of Electro-Fenton Process Performance for COD and Reactive Blue 19 Removal from Aqueous Solution. Iran J Health Environ. 2013; 5(4): 433-44. [Persian]

17- Ammar HB, Brahim MB, Abdelhédi R, Samet Y. Enhanced degradation of metronidazole by sunlight via photoFenton process under gradual addition of hydrogen peroxide. J Mol Catal A Chem. 2016; 420: 222-7. doi: 10.1016/j.molcata.2016.04.029

18- Astereki S, Kamarehie B, Jafari A. 2-Chlorophenol removal of aqueous solution using advanced oxidation processes resulting from Iron/Persulfate and ultra Violet/Persulfate. Iran J Toxicol. 2016; 10(4): 1-8.

19- Boukari SO, Pellizzari F, Karpel Vel Leitner N. Influence of persulfate ions on the removal of phenol in aqueous solution using electron beam irradiation. J Hazard Mater. 2011; 185(2-3): 844-51. doi: 10.1016/j.jhazmat.2010.09.097.

20- Zazouli MA, Taghavi M. Phenol removal from aqueous solutions by electrocoagulation technology using iron electrodes: Effect of some variables. J Water Resour Prot. 2012; 4(11): 980-3. doi: 10.4236/jwarp.2012.411113

21- Homem V, Santos L. Degradation and removal methods of antibiotics from aqueous matrices-a review. J Environ Manage. 2011; 92(10): 2304-47. doi: 10.1016/j.jenvman.2011.05.023.

22- Nasseh N, Taghavi L, Barikbin B, Nasseri MA, Allahresani A. FeNi3/SiO2 magnetic nanocomposite as an efficient and recyclable heterogeneous fenton-like catalyst for the oxidation of metronidazole in neutral environments: Adsorption and degradation studies. Compos B Eng. 2019; 166: 328-40. doi: 10.1016/j.compositesb.2018.11.112

23- Chatterjee J, Rai N, Sar SK. Kinetic isotherm of amoxicillin antibiotic through adsorption and its removal by electrocoagulation. Orient J Chem. 2014; 30(2): 775-84. doi: 10.13005/ojc/300251

24- Moussavi G, Aghapour AA, Yaghmaeian K. The degradation and mineralization of catechol using ozonation catalyzed with MgO/GAC composite in a fluidized bed reactor. Chem Eng J. 2014; 249: 302-10. doi: 10.1016/j.cej.2014.03.059 